\title{
A HREM study of the atomic structure and the growth mechanism at the $\mathrm{YBa}_{2} \mathrm{Cu}_{3} \mathrm{O}_{7} / \mathrm{YSZ}$ interface
}

\author{
J.G. Wen, C. Traeholt and H.W. Zandbergen \\ National Centre for HREM, Laboratory of Materials Science, Delft University of Technology, \\ Rotterdamseweg 137, 2628 AL Delft. The Netherlands \\ K. Joosse, E.M.C.M. Reuvekamp and H. Rogalla \\ Department of Applied Physics, University of Twente, PO Box 217, 7500 AE Enschede, The Netherlands
}

Received 13 July 1993

Revised manuscript received 3 September 1993

\begin{abstract}
The interface between yttria-stabilized zirconia (YSZ) substrate and $\mathrm{YBa}_{2} \mathrm{Cu}_{3} \mathrm{O}_{7}$ (YBCO) film was studied by high-resolution electron microscopy. In all specimens we have observed an intermediated layer of $\mathrm{BaZrO}_{3}$ located between the substrate $\mathrm{YSZ}$ and YBCO. The BaZrO 3 layer is composed of almost equally aligned domains being 4-8 $\mathrm{nm}$ in the lateral directions. Reaction products such as $\mathrm{Y}$ and $\mathrm{Cu}$ oxides were never observed in or close to the $\mathrm{BaZrO}_{3}$ reaction layer but they do occur in the $\mathrm{YBCO}$ film. The stacking sequence of $\mathrm{BaZrO}_{3} / \mathrm{YBCO}$ is predominantly $\left(\mathrm{BaZrO}_{3}\right)-\mathrm{ZrO}_{2}-\mathrm{BaO} / \mathrm{CuO}-\mathrm{BaO}-(\mathrm{YBCO})$ with $\mathrm{CuO}$ layer as the beginning YBCO layer. Sometimes a stacking sequence $\left(\mathrm{BaZrO}_{3}\right)-\mathrm{ZrO}_{2}-\mathrm{BaO} / \mathrm{BaO}-\mathrm{CuO}_{2}-(\mathrm{YBCO})$ with a $\mathrm{BaO}$ layer as the beginning YBCO layer was observed. This stacking is related to a dislocation with Burgers vector $a^{\prime} / 2[111]$, where $a^{\prime}=0.42 \mathrm{~nm}$ is the lattice constant of the cubic $\mathrm{BaZrO}_{3}$. Three main epitaxial relations $\left(0^{\circ}, 45^{\circ}, 9^{\circ}\right)$ between $\mathrm{YSZ}$ and $\mathrm{YBCO}$ were observed. These can be explained by near-coincidence site lattices $\sigma=25, \sigma=49$ and $\sigma=13$ (for a YSZ substrate). Usually the (001) plane of the YBCO film is parallel to the (001) plane of the $\mathrm{BaZrO}_{3}$ layer and parallel to the substrate surface. In case YBCO is grown on an inclined YSZ substrate, the (001) plane of the YBCO film is parallel to the substrate surface and thus not parallel to the (001) plane of the YSZ substrate.
\end{abstract}

\section{Introduction}

Yttria-stabilized zirconia (YSZ) is one of the most common substrates for growing $\mathrm{YBa}_{2} \mathrm{Cu}_{3} \mathrm{O}_{7}$ (YBCO) superconducting films. With YBCO films on YSZ one has never quite achieved such high critical currents as YBCO films on $\mathrm{MgO}$ and $\mathrm{SrTiO}_{3}$. YSZ, similar to $\mathrm{MgO}$, has also been used successfully as a diffusion barrier on the more reactive substrates such as $\mathrm{Si}, \mathrm{GaAs}$, and $\mathrm{Al}_{2} \mathrm{O}_{3}$ [1-3]. A combined $\mathrm{YSZ} /$ $\mathrm{Y}_{2} \mathrm{O}_{3}$ buffer layer has been used when growing a YBCO film on Si [4].

YSZ has a lattice constant $\left(a_{0}=0.514 \mathrm{~nm}\right)$ which is quite different from that of YBCO. Despite the large lattice mismatch, epitaxial YBCO films have been obtained on an (001) YSZ substrate. The dissimilarity of crystal structures and lattice constants between YBCO and YSZ results in the feature that epitaxial $c$-axis films grown on YSZ are frequently polycrystalline and have several in-plane orientations [5]. Epitaxy may occur with the YBCO a-axis parallel to the substrate [ 100$]$ or [110], causing $45^{\circ}$ grain boundaries. However, a special epitaxy with the YBCO $a$-axis making an angle of about $9^{\circ}$ with the substrate [100] was also found [6]. In our paper these epitaxies are defined as $0^{\circ}, 45^{\circ}$, and $9^{\circ}$ epitaxy, respectively. Alarco et al. [7] reported that the dominant orientation relationship at low temperatures $\left(650^{\circ} \mathrm{C}\right)$ was $45^{\circ}$ epitaxy while at higher temperatures $\left(750^{\circ} \mathrm{C}\right)$ it was $0^{\circ}$ epitaxy. Fork et al. [6] grew homoepitaxial YSZ and heteroepitaxial $\mathrm{CeO}_{2}$ on YSZ single-crystal substrates and reported that this procedure dramatically improves the epitaxy of YBCO and reduces the number of low- and high-angle grain boundaries. Their result indicates that seed layers deposited prior to YBCO are more effective 
for controlling the YBCO epitaxy than is temperature or pressure. They explain the $9^{\circ}$ epitaxy as due to a low energy $\Sigma 5$ grain boundary between YBCO and YSZ substrate.

The interfaces between thin films of YBCO and various substrates were widely studied by transmission electron microscopy (TEM) [8-15]. On the reaction layer of YBCO and YSZ substrate was reported by several groups [11-13]. Bardal et al. reported that in case of growth of YBCO on Si by using a combined $\mathrm{YSZ} / \mathrm{Y}_{2} \mathrm{O}_{3}$ buffer layer, the first layer of the $\mathrm{YBCO}$ at the interface $\mathrm{Y}_{2} \mathrm{O}_{3} / \mathrm{YBCO}$ is found to be a $\mathrm{BaO}$ layer [16]. Fork et al. [6] reported that approximately monolayer amounts of $\mathrm{CuO}, \mathrm{BaO}$, and $\mathrm{BaZrO}_{3}$ deposited on the YSZ surface prior to the deposition of YBCO result in large differences in the YBCO film orientation. They found that $\mathrm{CuO}$ and $\mathrm{BaZrO}_{3}$ induce a $45^{\circ}$ epitaxy whereas a monolayer of $\mathrm{BaO}$ results in a $9^{\circ}$ orientation indicating that the presence of a single layer can direct the epitaxy. The results of Fork et al. [6] are rather surprising in view of the presence of a $1-3 \mathrm{~nm}$ thick reaction layer of $\mathrm{BaZrO}_{3}$ between the YBCO thin film and the YSZ support.

In this paper we report a HREM study of the atomic structures at the $\mathrm{YBCO} / \mathrm{YSZ}$ interface. In particular the role of the $\mathrm{BaZrO}_{3}$ intermediate layer in the orientation of the YBCO film is outlined and discussed.

\section{Experimental}

All different layers in one sample on YSZ substrate are deposited in situ, using $90^{\circ}$ off-axis magnetron sputtering. The sputter gas is a mixture of $\mathrm{Ar}$ and $\mathrm{O}_{2}$, with $\mathrm{Ar}: \mathrm{O}_{2}=3: 2$ and a total pressure of $0.13 \mathrm{mbar}$. The substrate temperature is typically $740^{\circ} \mathrm{C}$. After deposition, the sample is cooled down in 800 mbar oxygen with $20 \mathrm{~K} / \mathrm{min}$.

Cross-section specimens for transmission electron microscopy were mechanically grinned directly down to a thickness less than $10 \mu \mathrm{m}$. A specimen was mounted on a single hole copper grid (with diameter $0.8 \mathrm{~mm}$ ). During ion milling (Gatan duo mill 600), the specimen was not rotated and was oriented such that the thin-film side was facing away from the ion gun. By using this method, the substrate YSZ was used as an ion beam blocker to minimize preferential milling of the YBCO film. The ion-milling conditions are: acceleration voltage $4.5 \mathrm{kV}$, gun current $0.5 \mathrm{~mA}$, ion-milling angle $15^{\circ}$ and no liquid-nitrogen cooling. When color fringes (thin film reflection) appear on the edge of the specimen an ion-polishing procedure is applied to thin the specimen to electron transparency with the conditions: acceleration voltage $3 \mathrm{kV}$, gun current $0.3 \mathrm{~mA}$, ion-milling angle $8^{\circ}$. This specimen-preparation technique provides large thin areas which enables one to check the thin-film quality by HREM over an area of more than $300 \mu \mathrm{m}$. More details of the sample preparation were reported elsewhere [17].

Some of our samples are ultra-thin YBCO films (less than 10 unit cells) which are covered by a $\mathrm{SrTiO}_{3}$ layer. When we prepare a TEM sample for these ultra-thin films by the above method, we found that these YBCO films can easily become amorphous. By coating both sides of the cross-section with gold after grinning, in order to make a good thermal and electrical contact between ultra-thin YBCO film and the copper grid (glued by silver powder glue), the amorphization could be prevented. In this case the sample was ion milled only from one side till color fringes appeared and then the other side was ion polished to electron transparency.

Electron microscopy was performed with a Philips CM30ST electron microscope operating at $300 \mathrm{kV}$ and equipped with a field-emission gun and side-entry $\pm 25^{\circ}$ tilt specimen holder. It is equipped with an energy dispersive X-ray (EDX) analysis detector with a Be window. The field-emission gun enables one to focus the electron beam into a small probe (minimum $1 \mathrm{~nm}$ ) for EDX analysis. The HREM images were recorded at a defocus about $-40 \mathrm{~nm}$ at which all cations are imaged as dark dots, and/or at about $-80 \mathrm{~nm}$ where the cations are imaged as white dots. Images were digitized with about 50 pixels per $\mathrm{nm}$. These images were noise reduced by averaging each pixel over itself and its eight neighbors.

\section{Results}

Electron diffraction shows quite frequently that when the YSZ substrate is in perfect [100] orientation the YBCO lattice is slightly tilted from a per- 
fect [100] orientation. In general this tilt is less than one degree. However, it does influence the HREM imaging. One has to choose whether one takes either the YBCO lattice or the YSZ lattice in perfect orientation or somewhere in between. In general the YBCO lattice was oriented as perfect as possible.

For all specimens an intermediate layer between YSZ and YBCO was observed (see fig. 1). The thickness of this intermediate layer ranged from $2 \mathrm{~nm}$ to $5 \mathrm{~nm}$. EDX analysis using spot sizes of $2 \mathrm{~nm}$ showed that the composition of this intermediate phase contains $\mathrm{Ba}$ and $\mathrm{Zr}$ ( $\mathrm{O}$ cannot be detected with the system used). This composition in combination with the square-like structure image with a spacing of $4.2 \AA$ indicates that the intermediate phase is
$\mathrm{BaZrO}_{3}$ formed by a reaction of YBCO and YSZ [18]. In general the interface between YSZ and $\mathrm{BaZrO}_{3}$ is somewhat rougher than the interface between $\mathrm{BaZrO}_{3}$ and $\mathrm{YBCO}$. At the YSZ/YBCO interface single unit-cell steps of YSZ do occur while at the $\mathrm{BaZrO}_{3} / \mathrm{YBCO}$ interface steps do occur corresponding to a whole unit cell of YBCO. Antiphase boundaries were only seldomly observed in the YBCO film at the $\mathrm{BaZrO}_{3} / \mathrm{YBCO}$ interface.

The $\mathrm{BaZrO}_{3}$ contains a lot of small domains. The orientations of different domains are more or less the same while the domain boundaries are small. The domain size along the interface direction is about $4 \mathrm{~nm}$ to $8 \mathrm{~nm}$.

The most dominant orientation relation between

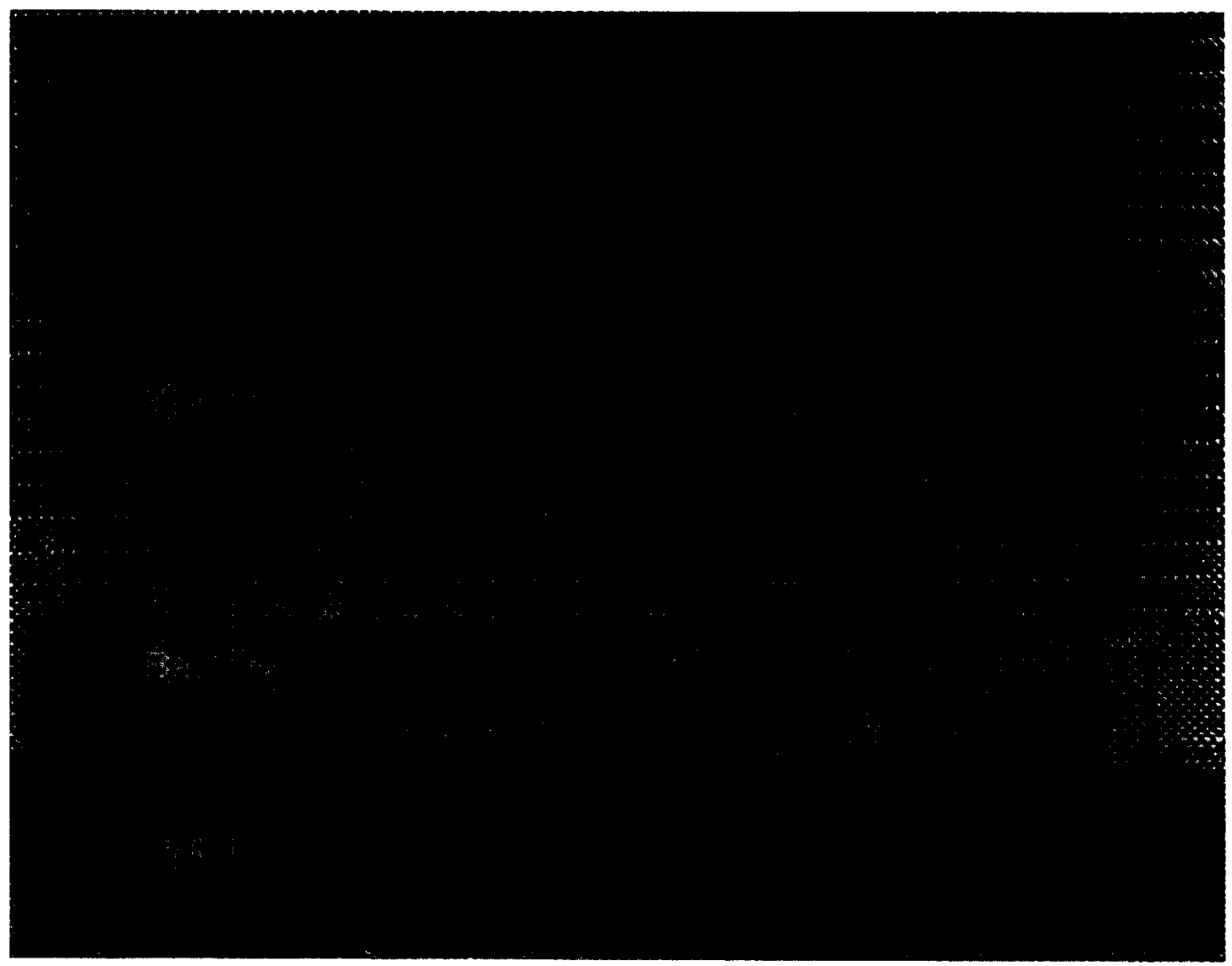

Fig. 1. HREM image of a YBCO film on a YSZ substrate taken along [110] of YSZ at focus value $-40 \mathrm{~nm}$. A reaction layer BaZrO from YSZ and $\mathrm{YBCO}$ is observed. Steps at the $\mathrm{BaZrO}_{3} / \mathrm{YBCO}$ interface correspond to a whole unit cell of $\mathrm{YBCO}$. The black arrow-head indicates the $\mathrm{CuO}$ layer as the beginning layer of the YBCO film. The white arrow indicates a stacking fault. There are interfacial dislocations at the interface on looking along the [111] and [111] direction of YSZ (indicated by two white arrows). 
the YBCO lattice and the YSZ substrate is a $45^{\circ} \mathrm{ep}-$ itaxy (see fig. 1), whereby the substrate is in the [110] orientation and YBCO in the [100] orientation. The orientation of the $\mathrm{BaZrO}_{3}$ layer is nearly $\left(<1^{\circ}\right)$ along the $[100]$ direction of the YBCO lattice. As can be seen in fig. 1 misfit dislocations do occur at the $\mathrm{BaZrO}_{3} / \mathrm{YSZ}$ interface with a spacing close to seven unit cells of YSZ. Similarly, at the $\mathrm{BaZrO}_{3} / \mathrm{YBCO}$ interface one can observe misfit dislocations each eleven unit cells of YBCO.

Mostly the stacking sequence at the $\mathrm{BaZrO}_{3} / \mathrm{YBCO}$ interface is $\mathrm{BaZrO}_{3}-\mathrm{ZrO}_{2}-\mathrm{BaO} / \mathrm{CuO}-\mathrm{BaO}-\mathrm{CuO}_{2}-$ $\mathrm{Y}-\mathrm{CuO}_{2}-\mathrm{BaO}-\mathrm{YBCO}$. An example of this stacking is shown in fig. 2. At this focus, the $\mathrm{CuO}$ atomic layer is the brightest line in the YBCO lattice. Since $\mathrm{BaZrO}_{3}$ and $\mathrm{YBCO}$ have a perovskite-like lattice, it is likely that this lattice is continued across the in- terface as much as possible (a continuation of the $(\mathrm{Cu}, \mathrm{Zr}),(\mathrm{Ba} / \mathrm{Y}, \mathrm{Ba})$ and $\mathrm{O}$ sublattice $)$. This is also observed for the $\mathrm{YBCO} / \mathrm{SrTiO}_{3}$ lattice [8]. This means $\mathrm{ZrO}_{2}$ cannot be the atomic layer next to $\mathrm{CuO}$. Therefore, the two atomic layers on both sides of the first $\mathrm{CuO}$ layer of the YBCO film are two $\mathrm{BaO}$ layers, one of which is part of the YBCO lattice and the other part of the $\mathrm{BaZrO}_{3}$ lattice. One can see that the $\mathrm{Ba}$ atoms in the $\mathrm{BaO}$ layer on the $\mathrm{BaZrO}_{3}$ side next to this CuO layer disappear or are not imaged in the area of a dislocation. Around such a dislocation the atoms are shifted from their "normal" positions. The shifts are quite stronger in the $\mathrm{BaZrO}_{3}$ lattice. The insert in fig. 2 shows an intensity scan for three different $\mathrm{BaO}$ layers $\mathrm{A}, \mathrm{B}$, and $\mathrm{C}$. Layer $\mathrm{A}$ indicates the $\mathrm{BaO}$ layer next to the $\mathrm{CuO}$ layer on the side of $\mathrm{YBCO}$ film while layer $\mathrm{B}$ indicates the $\mathrm{BaO}$ layer next to the

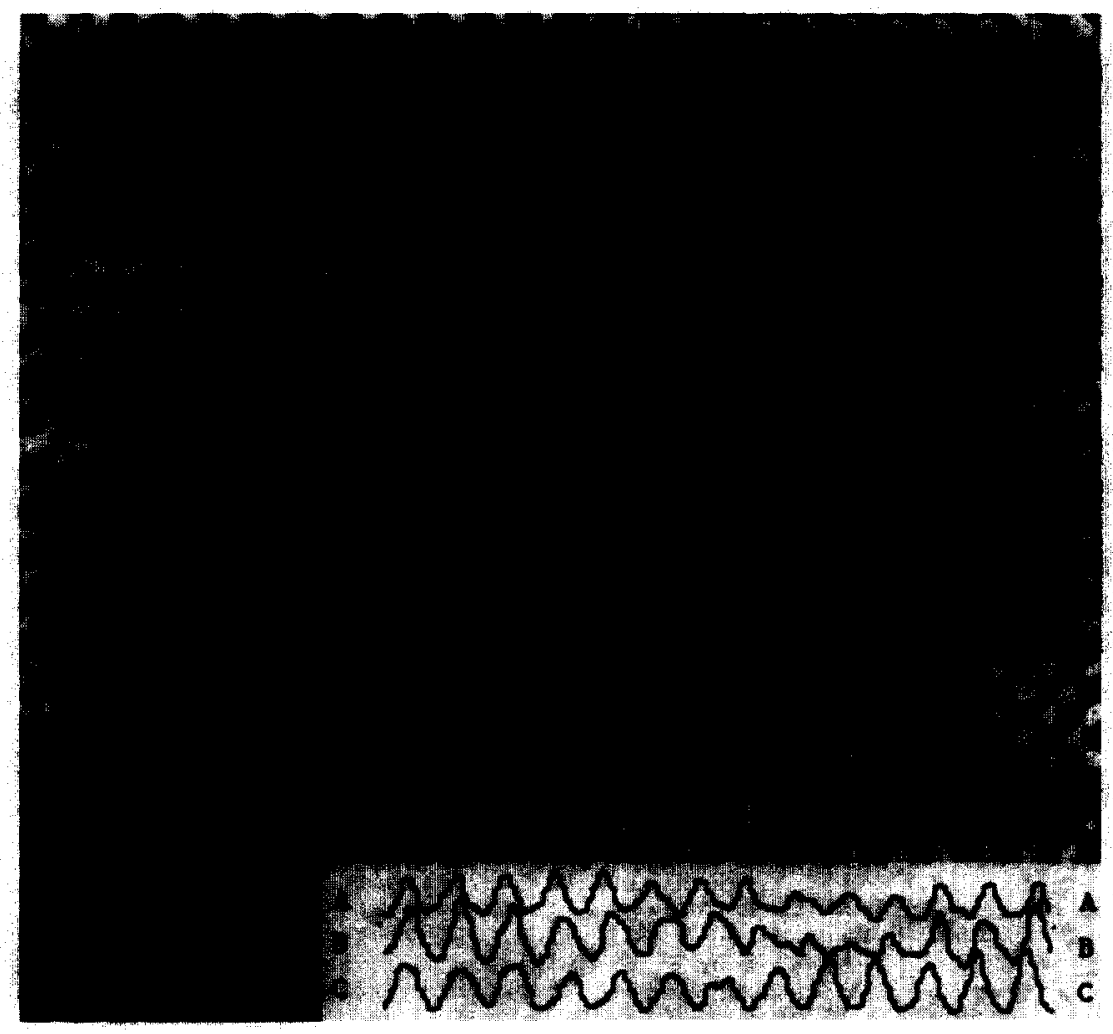

Fig. 2. An enlargement of fig. 1. The CuO layer as the beginning layer of YBCO is indicated by black arrow-heads. Two black lines indicate the lattice bending in the $\mathrm{BaZrO}_{3}$ lattice. The insert shows the scanning intensities for three different $\mathrm{BaO}$ layers. Layer $\mathrm{A}$ indicates the $\mathrm{BaO}$ layer next to the CuO layer on the side of $\mathrm{YBCO}$ film while layer $\mathrm{B}$ indicates the BaO layer next to the CuO layer on the side of the reaction layer. Layer $\mathrm{C}$ is the $\mathrm{BaO}$ layer in the reaction layer and is five unit cells of $\mathrm{BaZrO}_{3}$ away from the first $\mathrm{CuO}$ layer. A misfit dislocation can be observed. 
$\mathrm{CuO}$ layer on the side of reaction layer. Layer $\mathrm{C}$ is the $\mathrm{BaO}$ layer in the reaction layer and is five unit cells of $\mathrm{BaZrO}_{3}$ away from the $\mathrm{YBCO} / \mathrm{BaZrO}{ }_{3}$ interface. The spacing between two $\mathrm{Ba}$ atoms in layer $B$ is larger than that between two $B a$ atoms in the YBCO lattice (layer A). The spacing between two $\mathrm{Ba}$ atoms in the $\mathrm{BaZrO}_{3}$ lattice (layer $\mathrm{C}$ ) is larger than that between two $\mathrm{Ba}$ atoms in layer $\mathrm{B}$. In the regions which are next to the dislocation the spacing between two $\mathrm{Ba}$ atoms in layer $\mathrm{B}$ is in between that in layer A and layer C. It is difficult to tell whether the spacing in layer $B$ follows that of layer $A$ or layer C. Looking along the [001] direction of $\mathrm{BaZrO}_{3}$ at a grazing angle, one can see that the lattice in the $\mathrm{BaZrO}_{3}$ lattice bends away from the dislocation core and the discontinuation in the shifts of the atoms occurs at the $\mathrm{CuO}$ layer of YBCO. Thus, the CuO layer is the beginning layer of the YBCO lattice.

Not always the sequence $\mathrm{BaZrO}_{3}-\mathrm{ZrO}_{2}-\mathrm{BaO}$ / $\mathrm{CuO}-\mathrm{BaO}-\mathrm{CuO}_{2}-\mathrm{Y}-\mathrm{CuO}_{2}-\mathrm{BaO}-\mathrm{YBCO}$ is observed at the $\mathrm{BaZrO}_{3} / \mathrm{YBCO}$ interface. Figure 3 shows the existence of a stacking sequence $\mathrm{ZrO}_{2}-$ $\mathrm{BaO} / \mathrm{BaO}-\mathrm{CuO}_{2}-\mathrm{Y}-\mathrm{CuO}_{2}-\mathrm{BaO}$. However, this sequence occurs in an area next to that having the dominant sequence. In the projection of fig. 3 at the position where the $\mathrm{CuO}$ layer disappears a dislocation with Burgers vector $a^{\prime} / 2$ [111] appears as an $a^{\prime} /$ 2 [101] dislocation (as indicated on the figure), indicating that the $\mathrm{ZrO}_{2}-\mathrm{BaO} / \mathrm{BaO}-\mathrm{CuO}_{2}-\mathrm{Y}-\mathrm{CuO}_{2}-$ $\mathrm{BaO}$ sequence occurs to fit the lattice mismatch between the $\mathrm{BaZrO}_{3}$ and $\mathrm{YBCO}$ lattices.

Two different types of orientation relations were frequently observed as well: a $0^{\circ}$ and $a \approx 9^{\circ}$ epitaxy. A $0^{\circ}$ epitaxy is shown in fig. 4. In this figure YSZ, $\mathrm{BaZrO}_{3}, \mathrm{YBCO}$ and $\mathrm{SrTiO}_{3}$ are all in the [100] orientation. A misfit dislocation can be observed in the $\mathrm{BaZrO}_{3}$ lattice each five unit cells of YSZ. For a $9^{\circ}$ epitaxy the $\mathrm{YBCO}$ and the $\mathrm{BaZrO}_{3}$ lattice have the same orientation. Due to the difference in orientation of the $\mathrm{YBCO} / \mathrm{BaZrO}_{3}$ lattice and the YSZ lattice atomic resolution can only be obtained for one set of lattices.

Figure 5 shows a HREM image of a YBCO thin film on a YSZ substrate taken along [100] of YSZ. The left and right parts of YBCO films are [110] oriented and [100] oriented, respectively, resulting in a $45^{\circ}$ grain boundary. The grain boundary is zigzagging parallel to the (100), (103) and (101) planes. Both parts of the YBCO films are of a c-oriented growth nature. The orientations of the related left and right parts of the $\mathrm{BaZrO}_{3}$ layer are [110] and close to [100] oriented, respectively. The boundary of YBCO does not start from the boundary of the $\mathrm{BaZrO}_{3}$.

The YBCO and YSZ lattices have an $0^{\circ}, \approx 9^{\circ}$ or $45^{\circ}$ relation also when the intermediate $\mathrm{BaZrO}_{3}$ has a different orientation from the YBCO. The different orientation for $\mathrm{YBCO}$ and $\mathrm{BaZrO}_{3}$ occurs rather seldomly, but in the cases it is present it is instructive for learning about the growth mechanism. It indicates that at least in these parts the YBCO lattice is grown in interaction with the YSZ lattice and not in interaction with the $\mathrm{BaZrO}_{3}$ lattice. Examples of such situations are shown in figs. 6 and 7. In fig. 6 the substrate is in the [100] orientation whereas the orientation of the right part of $\mathrm{BaZrO}_{3}$ is nearly along the [133] orientation (calculated from the lattice spacing of this grain). However, the YBCO is in [100] orientation over the whole area. In fig. 7 the YSZ substrate, YBCO, and $\mathrm{SrTiO}_{3}$ covering the YBCO are all of the [100] orientation except for the $\mathrm{BaZrO}_{3}$ layer. The $\mathrm{BaZrO}_{3}$ layer is slightly in-plane tilted $\left(<5^{\circ}\right)$ from the $[100]$ orientation.

The YBCO film was found to grow with its $c$-axis perpendicular to the surface of the substrate, irrespectively of whether the surface was a (001) plane or inclined from this orientation. Figure 8 shows an example of this. In this image there are a series of small steps on the surface of YSZ, corresponding to an inclination angle of the surface plane of $3^{\circ}-5^{\circ}$ from (001). The $c$ planes of the YBCO thin film are parallel to the surface plane of YSZ and thus not parallel to the (001) plane of YSZ.

The formation of the $\mathrm{BaZrO}_{3}$ lattice must lead to a $\mathrm{Y}$ and $\mathrm{Cu}$ enrichment of the deposited YBCO material. In particular for thin $\mathrm{YBCO}$ layers $\mathrm{Y}_{2} \mathrm{O}_{3}$ inclusions were observed in the YBCO film (see fig. 8). No inclusions of $\mathrm{Y}_{2} \mathrm{Cu}_{2} \mathrm{O}_{3}$ or $\mathrm{CuO}$ could be observed. In the case the YBCO film was covered with an $\mathrm{SrTiO}_{3}$ film the $\mathrm{SrTiO}_{3}$ was found to contain $\mathrm{Cu}$ by EDX analysis.

The YBCO film was found to contain two types of planar defects. The most frequently occurring defect was the presence of a double $\mathrm{CuO}$ layer corresponding to the $\mathrm{YBa}_{2} \mathrm{Cu}_{4} \mathrm{O}_{8}$ phase. The second planar defect consists of yet another extra layer, an example 


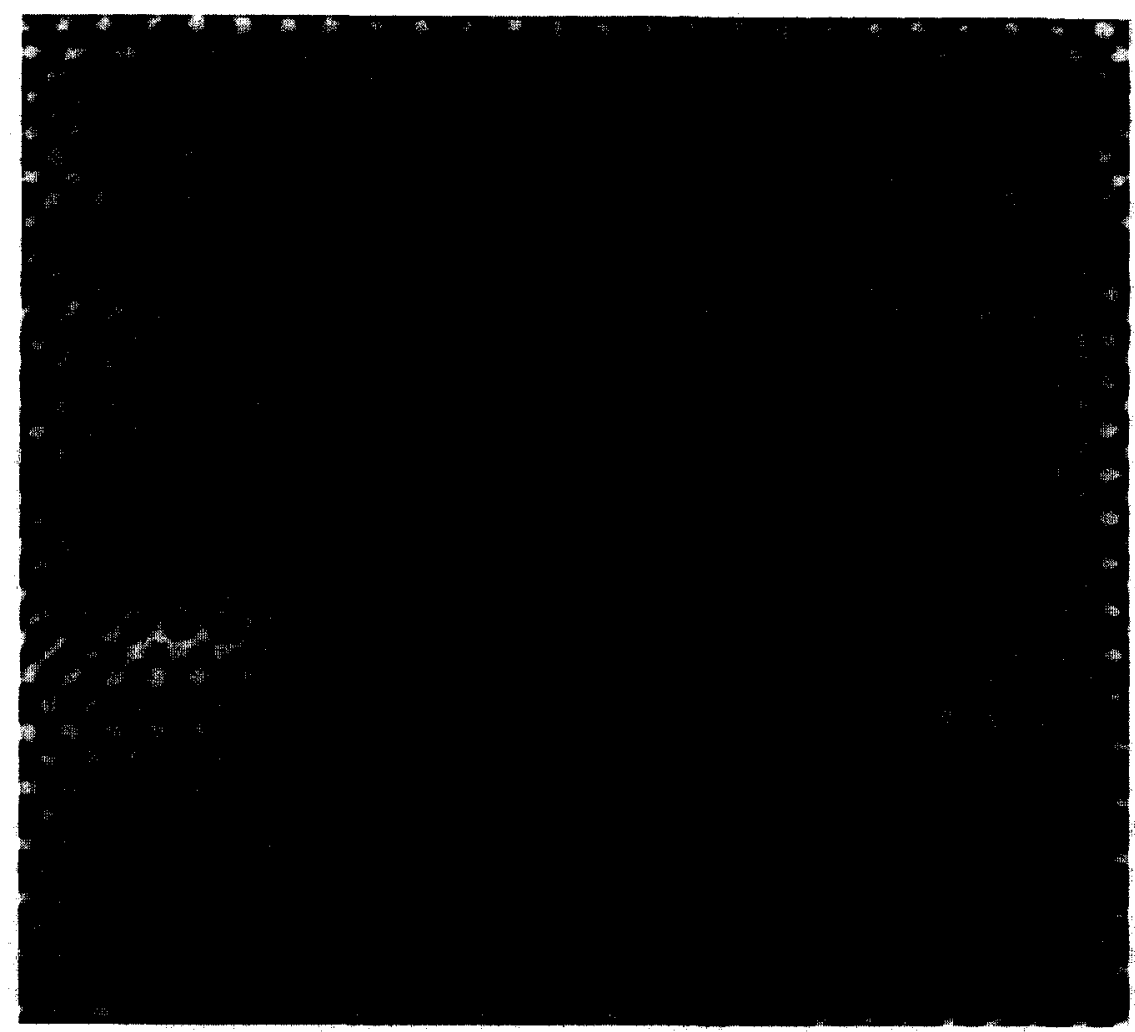

Fig. 3. Another area of the same film as fig. 2 at focus $-80 \mathrm{~nm}$. The CuO layer is indicated by a solid black arrow on the right side of the image. The $\mathrm{BaO}$ layers are indicated by two solid black arrow-heads on the left side. The CuO layer disappears at the white arrow. An $a^{\prime} /$ 2 [101] dislocation appears to be present in this projection.

of which can be seen in fig. 1. This defect can correspond to a phase $\mathrm{Y}_{1} \mathrm{Ba}_{2} \mathrm{Cu}_{5} \mathrm{O}_{x}[19]$ or $\mathrm{Y}_{1} \mathrm{Ba}_{3} \mathrm{Cu}_{4} \mathrm{O}_{x}$ [20].

\section{Discussion}

Many cross-sections of YBCO thin films of YSZ have been analyzed. Three kinds of epitaxial relations between the YBCO and the YSZ lattices are frequently observed: $45^{\circ}, 0^{\circ}$, and $9^{\circ}$, in order of abundance. Other angles of epitaxy, such as $5^{\circ}, 20^{\circ}$ etc, are found only seldomly. In all cases a $\mathrm{BaZrO}_{3}$ intermediate layer is observed. Regarding the $\mathrm{Ba}$ $\mathrm{ZrO}_{3}$ layer the following general observations were made:

(1) The thickness of the $\mathrm{BaZrO}_{3}$ layer varies from 1-3 nm.
(2) The $\mathrm{BaZrO}_{3}$ layer is "polycrystalline" with domain sizes along the interface of 4 to $8 \mathrm{~nm}$, whereby the misorientation between the domains is very small $\left(<1^{\circ}\right)$.

(3) The layer is mostly strained due to the mismatch, whereby the lattice distortion to adjust edge dislocations is much stronger in the $\mathrm{BaZrO}_{3}$ layer than in the adjacent YSZ or YBCO lattices.

(4) On the $\mathrm{BaZrO}_{3} / \mathrm{YSZ}$ interface one finds single unit-cell steps of $Y S Z$ whereas single $Y B C O$ unit-cell steps occur at the $\mathrm{YBCO} / \mathrm{BaZrO}_{3}$ interface.

(5) The $\mathrm{BaZrO}_{3}$ layer has almost always a $0^{\circ}$ orientation relation with the YBCO lattice.

Two types of stacking sequences are observed at the $\mathrm{YBCO} / \mathrm{BaZrO}_{3}$ interface:

(1) $-\mathrm{ZrO}_{2}-\mathrm{BaO} / \mathrm{CuO}-\mathrm{BaO}-\mathrm{CuO}_{2}-\mathrm{Y}-\mathrm{CuO}_{2}-\mathrm{BaO}-$

(2) $-\mathrm{ZrO}_{2}-\mathrm{BaO} / \mathrm{BaO}-\mathrm{CuO}_{2}-\mathrm{Y}-\mathrm{CuO}_{2}-\mathrm{BaO}-\mathrm{CuO}-$

The first type of interface is observed by far the 


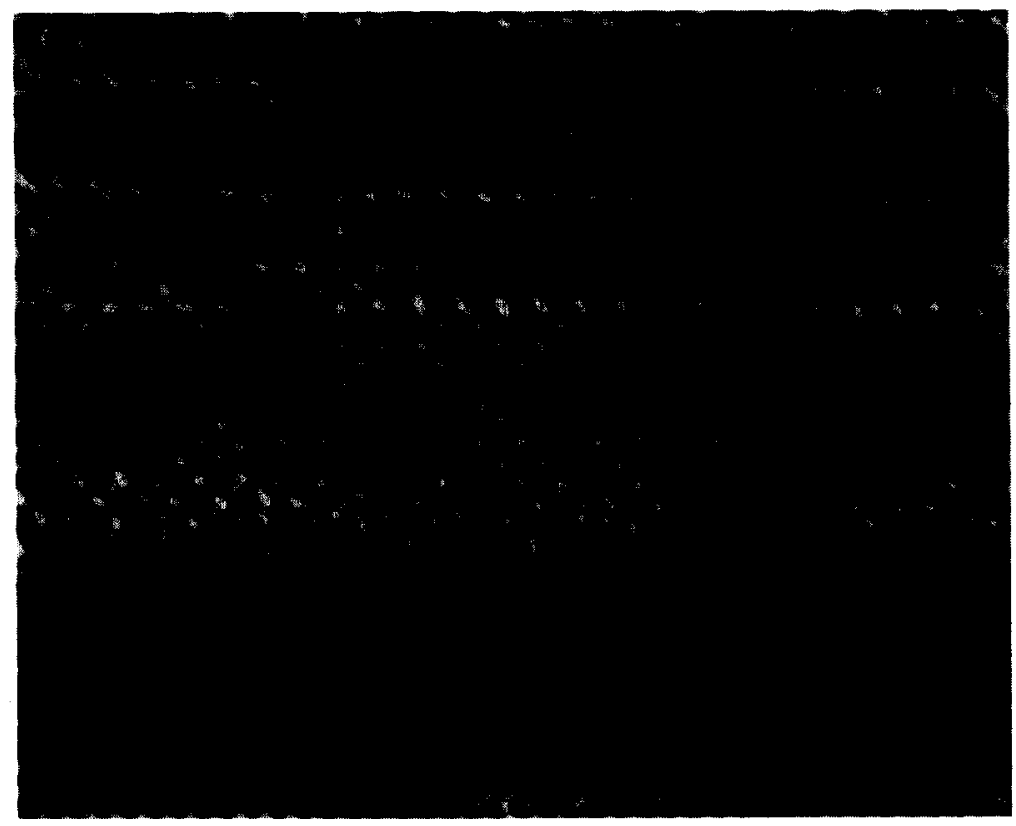

Fig. 4. HREM image of a YBCO thin-film $0^{\circ}$ epitaxy on a YSZ substrate covered by a $\mathrm{SrTiO}_{3}$ layer.

most frequently. We believe that the second one is only occurring due to the mismatch between the $\mathrm{BaZrO}_{3}$ and $\mathrm{YBCO}$ lattices (see below). In most cases the YBCO film grows with a $\mathrm{CuO}$ layer as the first layer regardless the orientation of the $\mathrm{BaZrO}_{3}$ layer. It is rather easy to determine the first YBCO layer if the orientation relation between the $\mathrm{BaZrO}_{3}$ and $\mathrm{YBCO}$ lattices is not $0^{\circ}$ as in fig. 7. However, in the case of a $0^{\circ}$ relation it is more difficult because the last $\mathrm{BaZrO}_{3}$ layer is a $\mathrm{BaO}$ layer which is oriented the same way as a "normal" $\mathrm{BaO}$ layer in YBCO, except for the lattice difference. Due to the lattice mismatch between the lattices of $\mathrm{BaZrO}_{3}$ and $\mathrm{YBCO}$, dislocations will occur at more or less regular intervals. In the interface regions halfway between these dislocation regions the lattice of $\mathrm{YBCO}$ and $\mathrm{BaZrO}_{3}$ are almost "in phase" and in these non-strained regions the question whether the $\mathrm{BaO}$ layer is part of the $\mathrm{BaZrO}_{3}$ or $\mathrm{YBCO}$ lattice is trivial. One can check whether the spacings of the $\mathrm{Ba}$ atoms in the $\mathrm{BaO}$ layer under consideration are close to those of the $\mathrm{BaZrO}_{3}$ or the YBCO lattice. By comparison one can see that the $\mathrm{BaO}$ lattice follows neither $\mathrm{YBCO}$ nor the $\mathrm{BaZrO}_{3}$ lattice, because of the lattice bending in the $\mathrm{BaZrO}_{3}$ lattice. Due to lattice bending to accommodate for the lattice mismatch a change in the 3-5 atomic layers in the $\mathrm{BaZrO}_{3}$ layer adjacent to the $\mathrm{YBCO}$ lattice can be observed. The lattice bending in the $\mathrm{BaZrO}_{3}$ lattice is much more dominant than that in the YBCO lattice adjacent to the $\mathrm{BaZrO}_{3} / \mathrm{YBCO}$ interface. Whereas the structure image of the CuO layer at this interface remains almost unchanged across the region of lattice mismatch, the first three atomic layers of the $\mathrm{BaZrO}_{3}$ lattice are strongly bend and the blackdot pattern of the first layer $(\mathrm{BaO})$ of the $\mathrm{BaZrO}_{3}$ lattice becomes vague at the actual dislocation site. This observation in combination with the better fit of the $\mathrm{BaO}$ layer at the interface in the non-strained regions with the $\mathrm{BaZrO}_{3}$ lattice and the observation that in non- $0^{\circ}$ oriented interfaces the first YBCO layer is a $\mathrm{CuO}$ layer leads us to the conclusion that in almost all cases (except for type (2) stacking) the first layer of the YBCO lattice is a CuO layer.

The interface of $\mathrm{YSZ}$ and the $\mathrm{BaZrO}_{3}$ layer is rougher compared with the $\mathrm{BaZrO}_{3} / \mathrm{YBCO}$ interface. The orientation relations between YSZ and $\mathrm{BaZrO}_{3}$ are predominantly $0^{\circ}$ and $45^{\circ}$. In both the cases of $0^{\circ}$ epitaxy and $45^{\circ}$ epitaxy, misfit dislocations are present at the interface. The misfit strain is mainly relieved by misfit dislocations. The small mi- 


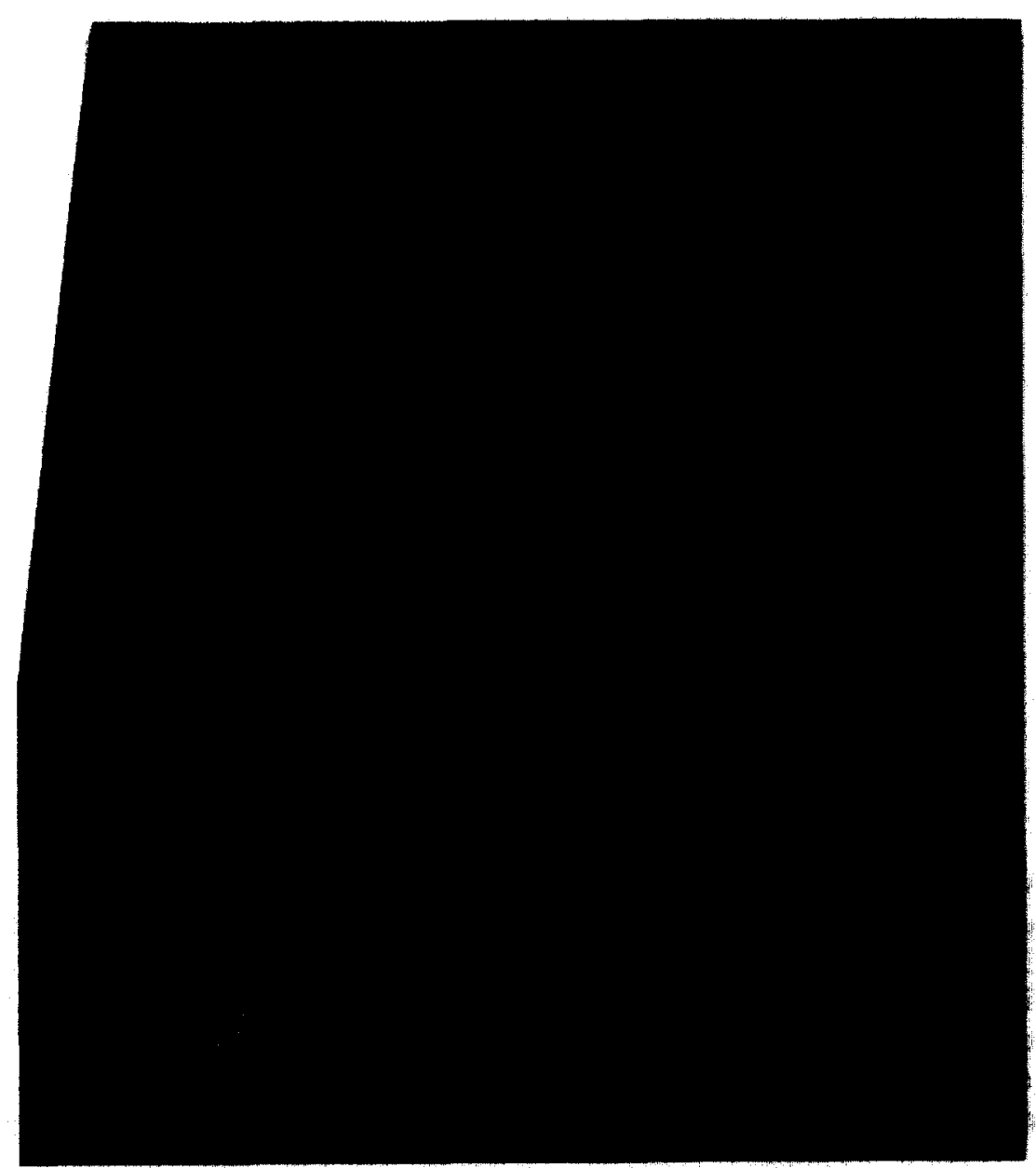

Fig. 5. HREM image of a YBCO thin film on a YSZ substrate taken along [100] of YSZ. The left and right parts of the YBCO films are [110] oriented and [100] oriented, respectively, resulting in a $45^{\circ}$ grain boundary. The grain boundary is zigzagging parallel to the $(100),(103)$ and (101) planes. The orientations of the related left and right parts of the $\mathrm{BaZrO}_{3}$ layer are [110] and close to [100] oriented, respectively.

sorientation between domains in the $\mathrm{BaZrO}_{3}$ layer can also relieve small part of the strain.

The presence of a $\mathrm{BaZrO}_{3}$ reaction layer implies that the YBCO-substrate interface in YBCO on YSZ samples has to be characterized by three interfaces: $\mathrm{YSZ} / \mathrm{BaZrO}_{3}, \mathrm{YSZ} / \mathrm{YBCO}$ and $\mathrm{BaZrO}_{3} / \mathrm{YBCO}$. In this respect the time of formation of the $\mathrm{BaZrO}_{3}$ intermediate layer (before, during or after formation of the first YBCO layers) is crucial for the understanding of the mechanism of growth of YBCO on YSZ. If the $\mathrm{BaZrO}_{3}$ layer forms immediately, the orientation of the YBCO layer will be determined by the interactions at the $\mathrm{YSZ} / \mathrm{BaZrO}_{3}$ and $\mathrm{BaZrO}_{3}$ /
YBCO interfaces. On the other hand, if the $\mathrm{BaZrO}_{3}$ layer is formed after the first layers of YBCO are formed, the orientation of the YBCO layer is only determined by the interaction at the YSZ/YBCO interface. A more complex mechanism will occur if $\mathrm{YBCO}$ and $\mathrm{BaZrO}_{3}$ are formed approximately the same time, whereby at the early stage some surfaces of YSZ will contain YBCO and others $\mathrm{BaZrO}_{3}$.

If the $\mathrm{BaZrO}_{3}$ layer forms only slowly, it will have little or no impact on the in-plane texture of the YBCO film, since these layers will be formed after several YBCO layers are grown at which point the in-plane texture is essentially fixed. In this case the 


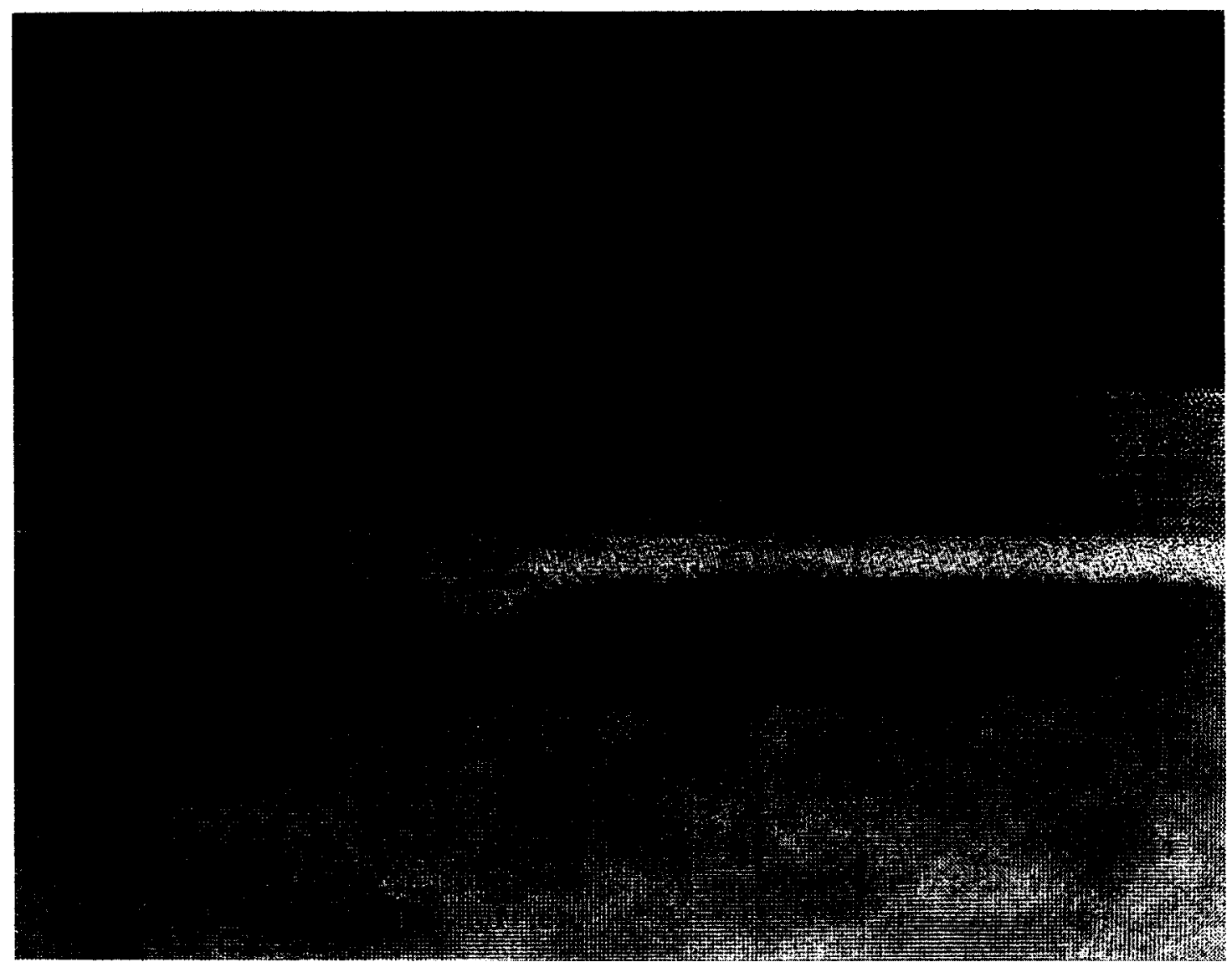

Fig. 6. HREM image of a thin YBCO film covered by $\mathrm{SrTiO}_{3}$ on a YSZ substrate takin along [100] of YSZ. The orientation of the left part of $\mathrm{BaZrO}_{3}$ is close to [100], while the orientation of the right part of $\mathrm{BaZrO}_{3}$ is nearly of the [133] orientation.

final distribution of reaction products will depend on the diffusion rate of $\mathrm{Ba}, \mathrm{Y}$ and $\mathrm{Cu}$ in the $\mathrm{YBCO}$ lattice at the temperature at which the film is grown. Since we have not observed the reaction products $\mathrm{Y}_{2} \mathrm{Cu}_{2} \mathrm{O}_{5}, \mathrm{Y}_{2} \mathrm{O}_{3}$ and $\mathrm{CuO}$ near the interface, either $\mathrm{Ba}$ must diffuse from the film to the interface or $\mathrm{Y}$ and $\mathrm{Cu}$ must diffuse away from the interface, or both. In both cases the film surface will be enriched with $\mathrm{Y}$ and $\mathrm{Cu}$ which can nucleate as second phases during further growth.

If the formation of the $\mathrm{BaZrO}_{3}$ layer is fast, the orientation of YBCO is mainly determined by the reaction layer $\mathrm{BaZrO}_{3}$. In this case one would expect the presence of antiphase boundaries in the YBCO lattice near the interface of $\mathrm{YBCO} / \mathrm{BaZrO}_{3}$, due to the presence of single unit-cell steps on the $\mathrm{BaZrO}_{3}$ surface. However, only steps of a single unit cell of YBCO, being three times that of $\mathrm{BaZrO}_{3}$, do occur at the $\mathrm{BaZrO}_{3} / \mathrm{YBCO}$ interface. This indicates that the $\mathrm{BaZrO}_{3}$ is not formed completely before the YBCO lattice is grown on top, but that $\mathrm{BaZrO}_{3}$ and YBCO are formed in the same time interval. Furthermore, we have observed in a number of specimens that regions exist in which the YBCO lattice is oriented $0^{\circ}$ or $45^{\circ}$ with respect to the YSZ lattice whereas the $\mathrm{BaZrO}_{3}$ lattice is strongly misoriented. Again, this indicates that in some, parts of the YBCO layer are formed by direct interaction with the YSZ lattice.

An intermediate process occurs if YBCO grows more or less at the same time as the formation of the reaction layer. In this case the YBCO film is not con- 


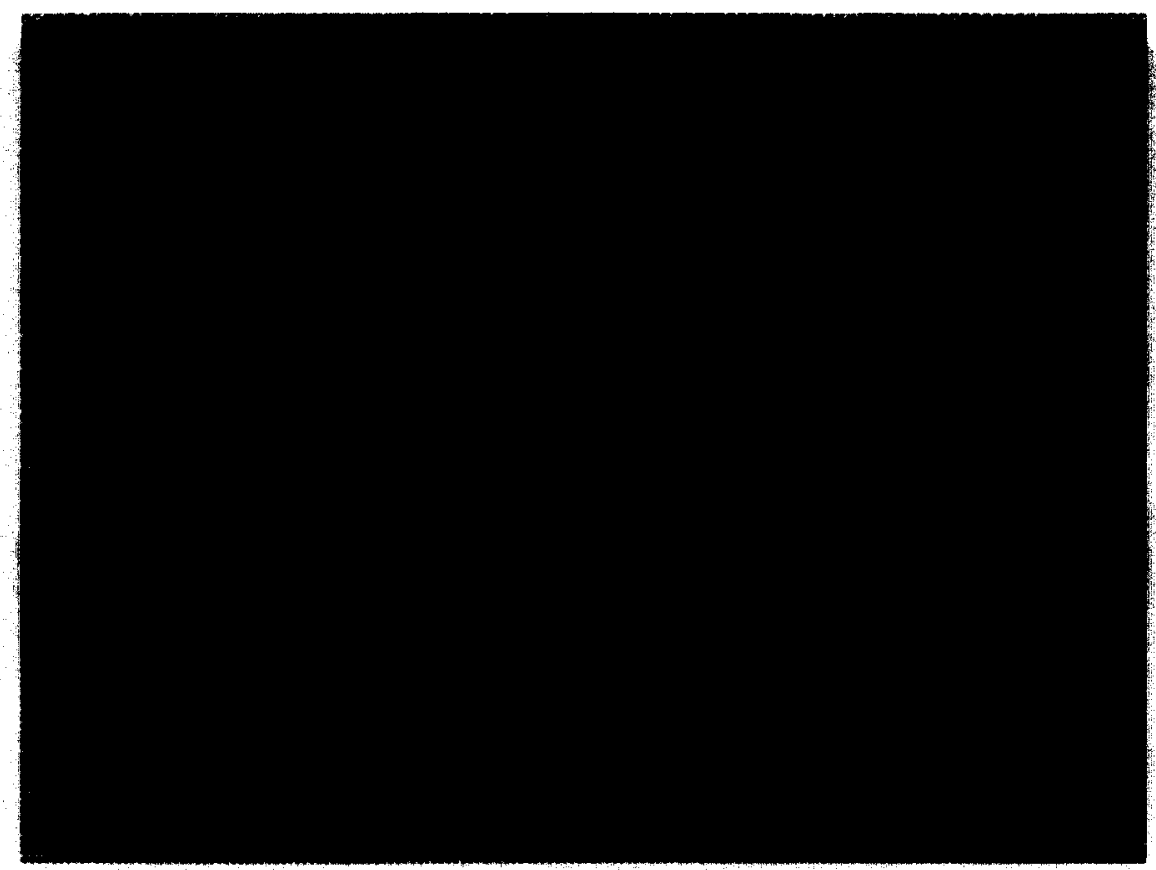

Fig. 7. HREM image of YBCO film covered by a $\mathrm{SrTiO}_{3}$ layer grown on a YSZ substrate. $\mathrm{YSZ}$ substrate, $\mathrm{YBCO}_{\text {, and } \mathrm{SrTiO}}$ are all of the $[100]$ orientation except for the $\mathrm{BaZrO}_{3}$ layer. The $\mathrm{BaZrO}_{3}$ layer is slightly in-plane tilted $\left(<5^{\circ}\right)$ from the $[100]$ orientation.

tinuous such that $\mathrm{Y}$ and $\mathrm{Cu}$ oxides can segregate out. For the slow growth and the intermediate process the $\mathrm{Y}$ oxides can become inclusions and the $\mathrm{Cu}$ oxide can move to the surface of the YBCO film in agreement with the results of Selinder et al. [21].

In order to understand the observed $0^{\circ}, 9^{\circ}$ and $45^{\circ}$ orientation relationships between the YSZ and YBCO lattices, near-coincidence site lattices (NCSL's) were calculated for three interfaces: YSZ/ $\mathrm{BaZrO}_{3}, \mathrm{BaZrO}_{3} / \mathrm{YBCO}$ and $\mathrm{YSZ} / \mathrm{YBCO}$. Only the in-plane orientations are considered, e.g. $(001)_{\mathrm{YSZ}}\left\|(001)_{\mathrm{BaZrO}_{3}}\right\|(001)_{\mathrm{YBCO}}$. As shown in fig. 9, since the (001) YSZ surface is a centered square lattice, the lattice can be simplified as a square lattice with a lattice constant of $3.63 \AA$. Therefore, the three interface surfaces are all simple square lattices.

The smaller the misfit $\delta$ and the higher the density of near-coincidence sites (i.e., small $\sigma_{\mathrm{A}}$ and $\sigma_{\mathrm{B}}$ ) are, the lower the interfacial energy is. However, the $\sigma$ values of the orientation relations should be used with some caution because the $\mathrm{BaZrO}_{3}$ layer is not a single crystal but composed of 4-8 $\mathrm{nm}$ large domains. The limited size of these domains will strongly re- duce the mismatch energy for the more unfavorable orientations. As such it might even be that orientations predicted to be less favorable by the NCSL calculations have a lower energy than some low- $\sigma$ orientations. Thus the NCSL calculations can only be used as an indication.

We calculated the orientation relations between these three interfaces. The results are listed in table 1. Since there are three interfaces, it is crucial to know which interface or two interfaces govern the orientation relation between YSZ and YBCO. It is not necessary to calculate the NCSL of the $\mathrm{BaZrO}_{3} /$ YBCO interface because a YBCO film has almost always a $0^{\circ}$ epitaxy relation with the $\mathrm{BaZrO}_{3}$ layer. Considering the orientation relations with minimal energy at the $\mathrm{YSZ} / \mathrm{BaZrO}_{3}$ interface, one can find these agree reasonably well with the experimentally observed interface. However, a much better agreement between theoretically predicted and experimentally determined orientation relations is obtained when one assumes that the YSZ/YBCO interface is governing the epitaxial relation.

By using a $\mathrm{YSZ} / \mathrm{BaZrO}_{3}$ interface we cannot ex- 


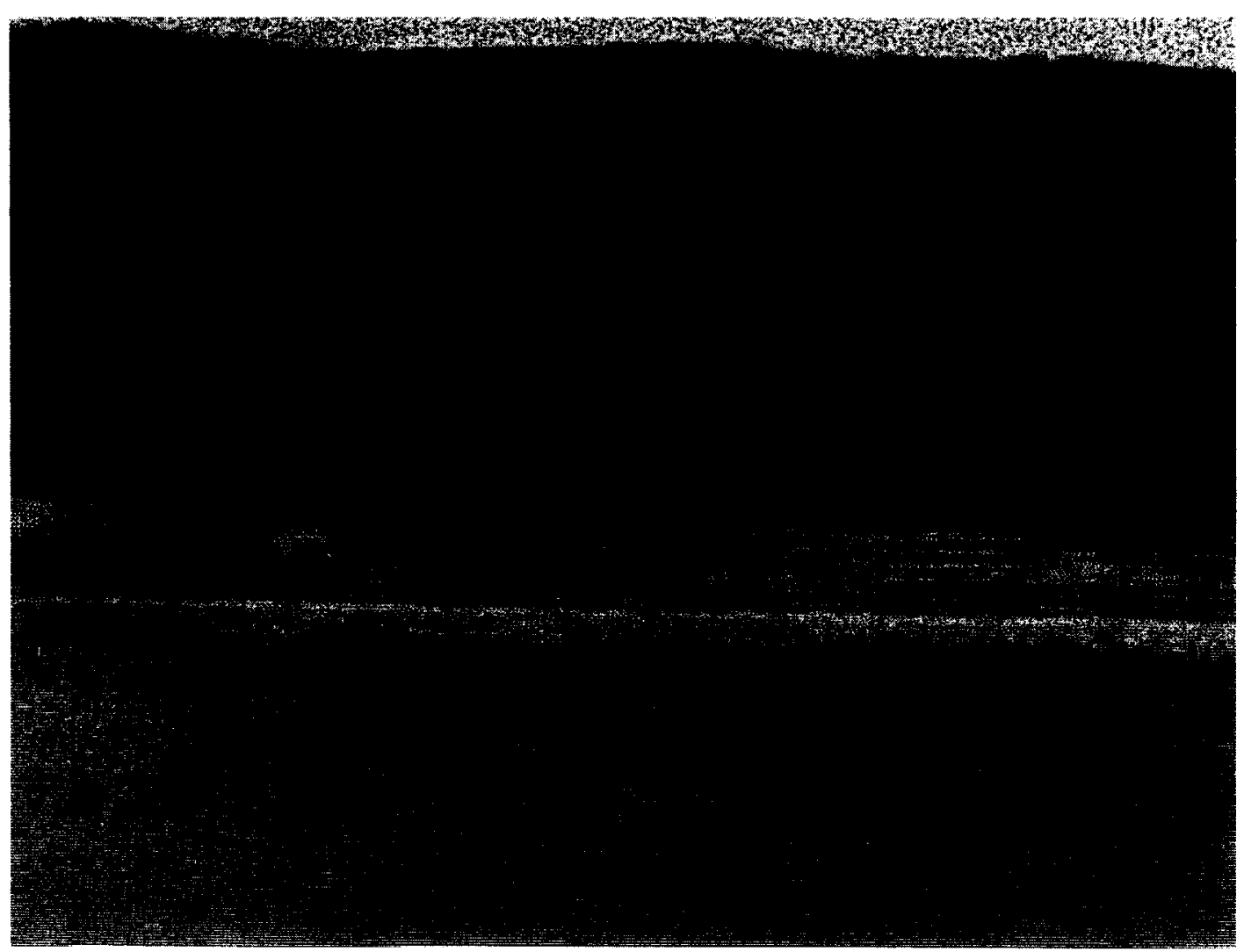

Fig. 8. HREM image of YBCO on a YSZ substrate covered by $\mathrm{SrTiO}_{3}$. There is a series of small steps on the surface of YSZ. The surface plane of YSZ is $3^{\circ}-5^{\circ}$ off the (001) plane of YSZ. The same (001) atomic plane of YSZ from the left to the right side is indicated by two black arrow-heads. The image shows that the $c$ planes of the YBCO thin film is parallel to the surface plane of YSZ and thus is not parallel to the (001) plane of YSZ. There is a $\mathrm{Y}_{2} \mathrm{O}_{3}$ inclusion (as indicated by arrows) in the YBCO film.

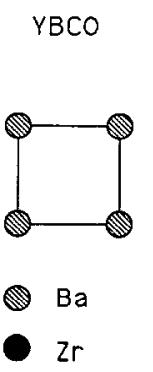

Fig. 9. Schematic structure for the $\mathrm{BaO}$ plane of a YBCO lattice and the Zr plane of the YSZ lattice. The (001) YSZ surface is a centered square lattice; the lattice can be simplified as a square lattice $\left(45^{\circ}\right.$ tilted $)$ with lattice constant $3.63 \AA$. plain the results reported by Fork et al. [6]. In view of the presence of the $\mathrm{BaZrO}_{3}$ reaction layer, Fork et al. [6] have reported rather unexpected results of the effect of the deposition of monolayers of $\mathrm{CuO}, \mathrm{BaO}$, and $\mathrm{BaZrO}_{3}$ on a $\mathrm{YSZ}$ surface, before the actual deposition of YBCO. They found that $\mathrm{CuO}$ and $\mathrm{Ba}-$ $\mathrm{ZrO}_{3}$ induce an almost complete $45^{\circ}$ epitaxy of $\mathrm{YBCO}$ whereas a monolayer of $\mathrm{BaO}$ results in an almost complete $9^{\circ}$ epitaxy. One would expect that a monolayer of any kind would hardly have any effect on the growth of YBCO since the starting composition is far from stoichiometric because of the formation of $\mathrm{BaZrO}_{3}$. The calculation shows that a $30^{\circ}$ epitaxy appears with the same probability as a $7.1^{\circ}$ epitaxy (if we consider this $7.1^{\circ}$ is the reason for $9^{\circ}$ epitaxy). But this is inconsistent with their obser- 
Table 1

Consider interface $\mathrm{A}$ as a lattice with unit vectors $a_{1}$ and $a_{2}$. The translation vectors for $\mathrm{A}$ can be written as $T_{\mathrm{A}}=k a_{1}+l a_{2}$ with the lengths given by a $\sqrt{\sigma_{\mathrm{A}}}$ where $\sigma_{\mathrm{A}}=k^{2}+l^{2}$. As is conventional, $\sigma$ instead of $\Sigma$ is used here to denote the near-CSL instead of a CSL. For interface $\mathrm{B}$, one has the lattice constant $b$, unit vectors $b_{1}$ and $b_{2}$, translation vectors $T_{\mathrm{b}}=m b_{1}+n b_{2}$, and $\sigma_{\mathrm{b}}=m^{2}+n^{2}$. The degree of coincidence of these two square lattices is measured by the percentage misfit $\delta=2\left(a \sqrt{\sigma_{A}}-b \sqrt{\sigma_{B}}\right) /\left(a \sqrt{\sigma_{A}}+b \sqrt{\sigma_{B}}\right)$. For a given near-CSL, the angles between the coincident vector and the principle axes of $\mathrm{A}$ and $\mathrm{B}$ are given by $\tan ^{-1}(l / k)$ and $\tan ^{-1}(n / m)$, respectively. Hence, the relative misorientation angle between the $A$ and $B$ axes is $\theta=\tan ^{-1}(l / k) \pm \tan ^{-1}(n / m)$. Here one finds lists of near-coincidence site lattices (CSL's) for three interfaces: $\mathrm{YSZ} / \mathrm{BaZrO}_{3}, \mathrm{YSZ} / \mathrm{YBCO}, \mathrm{BaZrO}_{3} / \mathrm{YBCO}$ calculated with $\sigma \leqslant 50$ and $\delta<2 \%$ except for three special orientations: $0^{\circ}, 45^{\circ}, 8.13^{\circ} .\left(^{*}\right)$ indicates the orientation was observed by experiments

\begin{tabular}{|c|c|c|c|c|c|c|c|}
\hline \multicolumn{3}{|c|}{ YSZ } & \multicolumn{3}{|c|}{$\mathrm{BaZrO}_{3}$} & \multirow[t]{2}{*}{ Misfit $\delta$} & \multirow[t]{2}{*}{ Misorientation $\theta$} \\
\hline$k$ & $l$ & $\sigma_{\mathrm{YSZ}}$ & $m$ & $n$ & $\sigma_{\mathrm{BnzZO} \mathrm{O}_{3}}$ & & \\
\hline 1 & 0 & 1 & 1 & 0 & 1 & $14.20 \%$ & $45^{\circ}$ \\
\hline 2 & 1 & 5 & 2 & 1 & 5 & $14.20 \%$ & $45^{\circ}, 8.13^{\circ}$ \\
\hline 3 & 0 & 9 & 2 & 2 & 8 & $8.33 \%$ & $0^{\circ}$ \\
\hline 3 & 2 & 13 & 3 & 1 & 10 & $1.34 \%$ & $7.1^{\circ}(*), 30^{\circ}$ \\
\hline 3 & 3 & 18 & 3 & 2 & 13 & $1.81 \%$ & $33.7^{\circ}$ \\
\hline 4 & 1 & 17 & 4 & 0 & 16 & $0.10 \%$ & $2.7^{\circ}(*), 25.3^{\circ}$ \\
\hline 5 & 1 & 26 & 4 & 2 & 20 & $1.34 \%$ & $7.1^{\circ}\left(^{*}\right), 30^{\circ}$ \\
\hline 5 & 3 & 34 & 4 & 3 & 25 & $0.91 \%$ & $39.2^{\circ}, 22.8^{\circ}\left(^{\circ}\right)$ \\
\hline 5 & 3 & 34 & 5 & 0 & 25 & $0.91 \%$ & $14^{\circ}$ \\
\hline 5 & 3 & 34 & 5 & 1 & 26 & $1.05 \%$ & $2.7^{\circ}(*), 25.3^{\circ}$ \\
\hline 5 & 0 & 25 & 3 & 3 & 18 & $1.96 \%$ & $0^{\circ}\left(^{*}\right)$ \\
\hline 7 & 0 & 49 & 6 & 0 & 36 & $0.95 \%$ & $45^{\circ}(*)$ \\
\hline \multicolumn{3}{|c|}{ YSZ } & \multicolumn{3}{|c|}{ YBCO } & Misfit $\delta$ & Misorientation $\theta$ \\
\hline$k$ & $l$ & $\sigma_{\mathbf{Y S Z}}$ & $m$ & $n$ & $\sigma_{\mathrm{YBCO}}$ & & \\
\hline 1 & 0 & 1 & 1 & 0 & 1 & $5.76 \%$ & $45^{\circ}$ \\
\hline 2 & 1 & 5 & 2 & 1 & 5 & $5.76 \%$ & $45^{\circ}, 8.13^{\circ}$ \\
\hline 3 & 0 & 9 & 2 & 2 & 8 & $0.13 \%$ & $0^{\circ}$ \\
\hline \multicolumn{3}{|c|}{$\mathrm{BaZrO}_{3}$} & \multicolumn{3}{|c|}{ YBCO } & Misfit $\delta$ & Misorientation $\theta$ \\
\hline$k$ & $l$ & $\sigma_{\text {BaZros }}$ & $m$ & $n$ & $\sigma_{\mathrm{YBCO}}$ & & \\
\hline 1 & 0 & 1 & 1 & 0 & 1 & $8.46 \%$ & $45^{\circ}$ \\
\hline 2 & 1 & 5 & 2 & 1 & 5 & $8.46 \%$ & $45^{\circ}, 8.13^{\circ}$ \\
\hline 2 & 2 & 8 & 3 & 0 & 9 & $2.57 \%$ & $0^{\circ}$ \\
\hline
\end{tabular}

vation. A possible explanation could be that some YBCO is formed on the surface of the YSZ support, thus steering the further growth of the bulk of the YBCO film as we suggested earlier in this discussion. From table 1 one can see the mismatches for $45^{\circ}$ and $8.13^{\circ}$ are the same. This supports the idea that a $9^{\circ}$ epitaxy occurs so frequently. This also indicates that YBCO directly grows on a YSZ substrate at the very beginning of the process. Then the orientation relations are determined by this interaction between YSZ and YBCO.

In the case of $0^{\circ}$ epitaxy shown in fig. $10(a)$, as we can see from fig. 4 , one can see that five unit cells of a YSZ substrate match with six unit cells of $\mathrm{BaZrO}_{3}$. This corresponds to $\sigma_{\mathrm{Ysz}}=24$ and $\sigma_{\mathrm{BaZrO}_{3}}=18$ as calculated in table 1 . For $45^{\circ}$ epitaxy (fig. $10(\mathrm{~b})$ ), as shown in fig. 2 or 3 , one can see seven unit cells of a YSZ substrate match with six unit cells of $\mathrm{BaZrO}_{3}$. This corresponds to $\sigma_{\mathrm{YsZ}}=49$ and $\sigma_{\mathrm{BaZrO}_{3}}=36$.

The terminating layer of the YBCO film was found to be a $\mathrm{CuO}$ layer. Similar arrangements with $\mathrm{CuO}$ as the terminating YBCO layer are observed in (001) grain boundaries in polycrystalline YBCO $[22,23]$, 


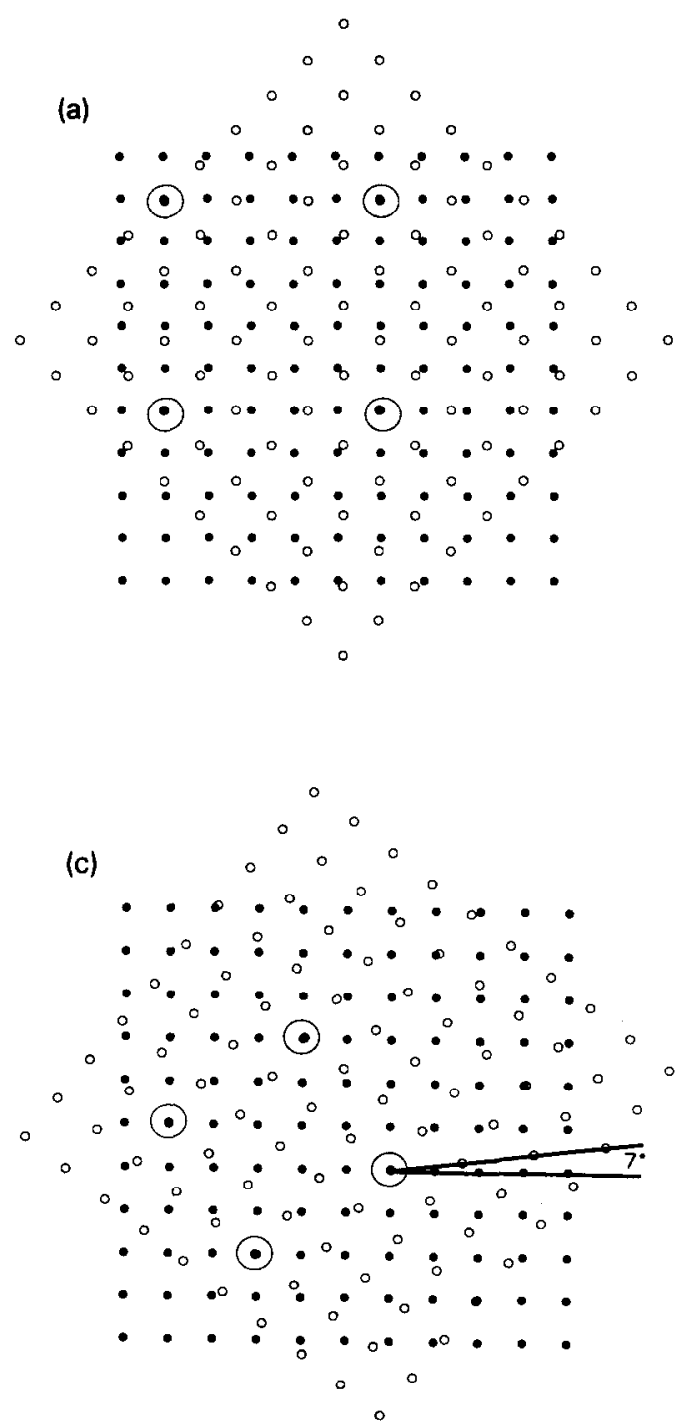

and at the interfaces $\mathrm{YBCO} / \mathrm{MgO}[9,10]$, and YBCO/amorphous YBCO [24]. These stacking sequences are in contrast with the sequence at the $\mathrm{SrTiO}_{3} / \mathrm{YBCO}$ interface, where the terminating layer of $\mathrm{YBCO}$ is a $\mathrm{BaO}$ layer. We have argued previously [8] that this is due to the strong interaction between YBCO and $\mathrm{SrTiO}_{3}$.

In the case of a $\mathrm{BaZrO}_{3} / \mathrm{YBCO}$ interface as well as for a $\mathrm{SrTiO}_{3} / \mathrm{YBCO}$ interface a perovskite structure is present at both sides of the interface. In the case of $[001]_{\mathrm{YBCO}}[001]_{\mathrm{BaZrO}_{3}}$ and $[100]_{\mathrm{YBCO}} \|[100]_{\mathrm{BaZrO}_{3}}$ as is observed in fig. 1 , the $(\mathrm{Cu}, \mathrm{Zr}),(\mathrm{Ba}, \mathrm{Ba} / \mathrm{Y})$ and $\mathrm{O}$ sublattice can continue (b)

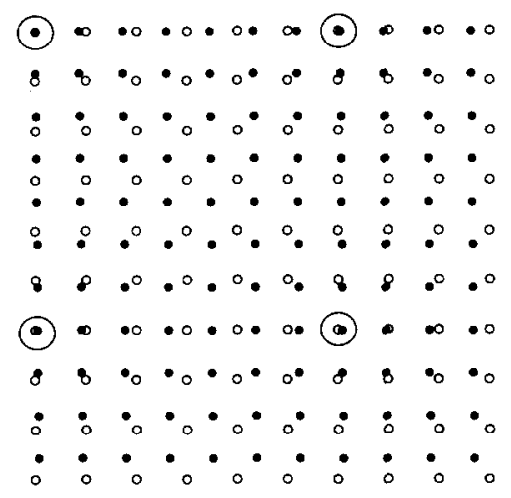

Fig. 10. (a), (b), and (c) Near-coincidence site lattices for a $0^{\circ}$, $45^{\circ}$, and $9^{\circ}$ epitaxy, respectively.

across the interface of $\mathrm{YBCO}$ and $\mathrm{BaZrO}_{3}$, since both structures are perovskite-like. The lattices of the $\mathrm{BaZrO}_{3}$ and $\mathrm{YBCO}$ have a rather large lattice mismatch $(-8 \%)$. For the stacking sequence $\mathrm{BaZrO}_{3}-$ $\mathrm{ZrO}_{2}-\mathrm{BaO} / \mathrm{CuO}-\mathrm{BaO}-\mathrm{CuO}_{2}-\mathrm{Y}-\mathrm{CuO}_{2}-\mathrm{BaO}-\mathrm{YBCO}$ this lattice mismatch leads to misfit dislocations ending in the interface as shown in fig. 2. For the stacking sequence $\mathrm{BaZrO}_{3}-\mathrm{ZrO}_{2}-\mathrm{BaO} /-\mathrm{BaO}-\mathrm{CuO}_{2}-$ $\mathrm{Y}-\mathrm{CuO}_{2}-\mathrm{BaO}-\mathrm{YBCO}$ two $\mathrm{BaO}$ layers are next to each other in a similar way as the two LaO layers in $\mathrm{La}_{2} \mathrm{CuO}_{4}$. This fact combined with a nearest neighbor consideration for the $\mathrm{Ba}$ atoms means that what appears to be an $a^{\prime} / 2[101]$ dislocation shown in fig. 
3 is more likely to be an $a^{\prime} / 2$ [111] dislocation.

The $c$ plane of a YBCO thin film tends to grow parallel to the surface of a substrate instead of parallel to the (001) plane of YSZ. With respect to the manufacturing of Josephson junctions this property can be beneficial as well as detrimental. In the first case a Josephson junction can be made at the kink of the surfaces meeting under a chosen angle. In the second case a YBCO-PrBCO-YBCO ramp Josephson junction obtained by masking and sputtering is unreliable because the sputtering of the YSZ support leads to inclined surfaces, thus adding unwanted extra grain boundaries due to out-of-plane misorientations [25], since these grain boundaries will have their own electrical characteristics.

\section{Conclusion}

The stacking sequence of a $\mathrm{YBa}_{2} \mathrm{Cu}_{3} \mathrm{O}_{7}$ film on a $\mathrm{BaZrO}_{3}$ layer is dominantly ( $\mathrm{YSZ}$ bulk) $-\mathrm{ZrO}_{2}-\mathrm{BaO} /$ $\mathrm{CuO}-\mathrm{BaO}-\mathrm{CuO}_{2}-$ (YBCO bulk). Sometimes the stacking sequence (YSZ bulk) $-\mathrm{ZrO}_{2}-\mathrm{BaO} / \mathrm{BaO}-$ $\mathrm{CuO}_{2}-\mathrm{Y}-(\mathrm{YBCO}$ bulk) can be observed. Three main epitaxial relations $\left(0^{\circ}, 45^{\circ}, 9^{\circ}\right)$ between YSZ and YBCO were observed. This can be explained by a near-coincidence site lattice $(\sigma=25,49,13$ for a YSZ substrate) between YSZ and the reaction layer $\mathrm{BaZrO}_{3}$. A YBCO film tends to grow following the orientation of the $\mathrm{BaZrO}_{3}$ layer, resulting in [100] of YBCO being parallel to [100] of the $\mathrm{BaZrO}_{3}$ layer. A YBCO film grows following the surface of the YSZ substrate instead of the $(001)$ atomic plane.

\section{Acknowledgements}

A. Delsing, H. Nieuwpoort, and C.D. de Haan are thanked for technical support. This research is financially supported by the Stichting voor Fundamenteel Onderzoek der Materie (FOM).

\section{References}

[1 ] D.K. Fork, D.B. Fenner, R.W. Barton, J.M. Phillips; G.A.N. Connell, J.B. Boyce and T.H. Geballe, Appl. Phys. Lett. 57 (1990) 1161.

[2] D.F. Fork, K. Nashimoto and T.H. Geballe, Appl. Phys. Lett. 60 (1992) 1621.

[3] X.D. Wu, R.E. Muenchausen, N.S. Nogar, A. Pique, R. Edwards, B. Wilkins, T.S. Ravi, D.M. Hwang and C.Y. Chen, Appl. Phys. Lett. 58 (1991) 304.

[4] W. Prusseit, S. Corsepius, M. Zwerger, P. Berberich, H. Kinder, O. Eibl, C. Jaekel, U. Breuer and H. Kurz, Physica C 201 (1992) 249.

[5] S.M. Garrison, N. Newman, B.F. Cole, K. Char and R.W. Barton, Appl. Phys. Lett. 58 (1991) 2168.

[6] D.K. Fork, S.M. Garrison, M. Hawley and T.H. Geballe, J. Mater. Res. 7 (1992) 1641.

[7] J.A. Alarco, G. Brorsson, Z.G. Ivanov, P.A. Nilsson, E. Olsson and M, Lofgren, Appl. Phys. Lett. 61 (1992) 723.

[8] J.G. Wen, C. Traeholt and H.W. Zandbergen, Physica C 205 (1993) 354.

[9] C. Traeholt and H.W. Zandbergen, Physica C, submitted.

[10] Y. Daitoh, K. Shimura, T. Terashima and Y. Bando, Bull. Inst. Chem. Res. (Kyoto Univ.) 70 (1993) 394.

[11] O. Eibl, Mater. Sci. Eng. B 10 (1990) 305.

[12] L.A. Tietz, C.B. Carter, D.K. Lathrop, S.E. Russek, R.A. Buhrman and J.R. Michael, J. Mater. Res. 4 (1989) 1072.

[13] H.W. Zandbergen, J.G. Wen, C. Traeholt and V. Svetchnikov, J. Alloys Compounds 195 (1993) 85.

[14] R. Ramesh, A. Inam, D.M. Hwang, T.S. Ravi, T. Sands, X.X. Xi, X.D. Su, Q. Li, T. Venkatesan and R. Kilaas, J. Mater. Res. 6 (1991) 2264.

[15] S.N. Basu, A.H. Carim and T.E. Mitchell, J. Mater. Res. 6 (1991) 1823 .

[16] A. Bardal, M. Zwerger, O. Eibl, J. Wecker and Th. Matthee, Appl. Phys. Lett. 61 (1992) 1243.

[17] C. Traeholt, J.G. Wen, V. Svetchnikov, A. Delsing and H.W. Zandbergen, Physica C 206 (1993) 318.

[18] M.J. Cima, J.S. Schneider, S.C. Peterson and W. Coblenz, Appl. Phys. Lett. 53 (1988) 710.

[19] H.W. Zandbergen, Physica C 193 (1992) 371.

[20] Domingues, M. Hervieu, B. Raveau, J. Karpinski, E. Kaldis and S. Rusiecki, J. Solid State Chem. 93 (1991) 316.

[21] T.I. Selinder, U. Helmersson, Z. Han, J.-E. Sundgren, H. Sjostrom and L.R. Wallenberg, Physica C 202 (1992) 69.

[22] H.W. Zandbergen, Physica C 194 (1992) 287.

[23] H.W. Zandbergen, R. Gronsky and G. Thomas, Phys. Status Solidi A 105 (1988).

[24] H.W. Zandbergen, R. Gronsky and G. Thomas, Physica C 153-155 (1988) 1002.

[25] E.M.C.M. Reuvekamp, M.A.J. Verhoeven, G.J. Gerritsma, J.G. Wen, H.W. Zandbergen and H. Rogalla, 1993 USAMRS meeting. 